\title{
Saccadic Intrusions in Strabismus
}

\author{
Kenneth J. Ciuffreda, OD, PhD; Robert V. Kenyon, PhD; Lawrence Stark, MD
}

\begin{abstract}
- Fixational eye movements were studied to determine the presence of and to quantify saccadic intrusions under monocular and binocular viewing conditions in subjects with intermittent strabismus, amblyopia without strabismus, or constant strabismus amblyopia. Saccadic intrusions were present under most test conditions in intermittent strabismus, were rarely observed in amblyopia withoul strabismus, and were prominent during monocular fixation with the amblyopic eye in constant strabismus amblyopia. This suggests that the presence of saccadic intrusions was related to strabismus and not amblyopia. There was no relationship between saccadic intrusion amplitude and visual acuity. Two possible mechanisms for producing intrusions are abnormally rapid regional visual adaptation and strabismus-induced fixation degradation.

(Arch Ophthalmol 97:1673-1679, 1979)
\end{abstract}

Saccadic intrusions refer to fast toand-fro horizontal eye movements observed in some patients, especially during fixation.".2 An intrusion consists of an error-producing saccade followed 150 to $500 \mathrm{~ms}$ later by an error-correcting saccade. Intrusions have amplitudes generally ranging from $0.5^{\circ}$ to $3.0^{\circ}$ and occur one to four times per second. While saceadic intrusions are frequently found in patients with neurologic disorders, ${ }^{2-8}$

Accepted for publication Oct 19, 1978.

From the School of Optometry, University of California, Berkeley. Dr Ciuffreda is now with the College of Optometry, State University of New York, New York. Dr Kenyon is now with Massachusetts Institute of Technology, Cambridge.

Reprint requests to College of Optometry, State University of New York, $100 \mathrm{E} 24$ th St, New York, NY 10010 (Dr Ciuffreda). they are occasionally observed in normal subjects (unpublished observations).

Saccadic intrusions have also been found during monocular fixation with the amblyopic eye in patients with strabismus amblyopia. Intrusions are evident in the fixation records presented by Mackensen ${ }^{9}$ and by von Noorden and Mackensen ${ }^{10}$; saccadic intrusions and large single saccades were also found by von Noorden and Burian, ${ }^{11}$ and more recently by Hess, ${ }^{12}$ during monocular fixation with the amblyopic eye. Schor and Flom ${ }^{13}$ found median fixational saccadic amplitude correlated with visual acuity in the amblyopic eye of strabismic amblyopes.

We expanded on previous studies by investigating fixational eye movements under both monocular and binocular test conditions, and by testing patients with a wide range of visual acuities in three clinically important and separable diagnostic groups: intermittent strabismus, amblyopia without strabismus, and constant strabismus amblyopia. We hoped that we might provide an indication of the cause and functional importance of saccadic intrusions by extending our study to include subjects with either intermittent strabismus or amblyopia without strabismus, both being diagnostic groups previously unstudied in a systematic manner.

\section{METHODS}

Horizontal eye movements were measured by a photoelectric technique. ${ }^{1+}$ Diodes were aimed at the limbus, and the amount of infrared light reflected from this region was monitored. The signals were proportional to the angle of ocular rotation. The response was linear over at least a $\pm 5^{\circ}$ range of movements with a resolution of 10 minutes of arc. An infrared emitter mounted between the diodes diffusely illuminated the eye. The overall bandwidth of the recording system was $75 \mathrm{~Hz}(-3 \mathrm{~dB})$. A chinrest and headrest, usually used with a bite bar covered with dental impression material, stabilized the head.

A minicomputer was used to generate a small (approximately 4 minutes), bright test spot on a display screen placed either 57 or $91 \mathrm{~cm}$ directly in front of the subject along the midline. Target luminance was always maintained at least $1 \log$ unit above screen luminance.

Fixational eye movements for the midline target position or $2.5^{\circ}$ or $5.0^{\circ}$ to either the left or right of midline were tested during monocular and binocular viewing conditions. During monocular testing, the nontested eye was prevented from seeing the target by occlusion with either a black eyepatch or a large partition. These methods of occlusion had no effect on eye movements.

Subjects were obtained from either the general refraction clinic or the orthoptics clinic at the School of Optometry. All had thorough vision examinations and were free of ocular or neurologic disease. Ages ranged from 15 to 33 years, with a mean age of 25.5 years. Subjects had either intermittent strabismus, amblyopia without strabismus, or constant strabismus amblyopia. The prescribed spectacles or contact lenses were worn during all testing. Table 1 summarizes complete clinical data of the subjects. Each subject granted informed consent after the nature of the procedure was fully explained.

\section{RESULTS}

The principal finding of our investigation was the presence of saccadic intrusions during fixation in subjects with strabismus. Saccadic intrusions were found during most fixation conditions in three of four subjects with intermittent strabismus. They were also prominent during monocular fixation with the amblyopic eye in four of five subjects with constant strabismus with amblyopia. Saccadic 


\begin{tabular}{|c|c|c|c|c|c|c|}
\hline \multicolumn{7}{|c|}{ Table 1.-Clinical Data of Subjects* } \\
\hline $\begin{array}{l}\text { Subject/ } \\
\text { Age, yr }\end{array}$ & Prescription & $\begin{array}{l}\text { Visual } \\
\text { Acuity }\end{array}$ & $\begin{array}{c}\text { Vergence } \\
\text { Abnormality }\end{array}$ & $\begin{array}{l}\text { Eccentric } \\
\text { Fixation }\end{array}$ & $\begin{array}{c}\text { Correspon- } \\
\text { dence }\end{array}$ & $\begin{array}{l}\text { Previous Surgery or } \\
\text { Orthoptics Therapy }\end{array}$ \\
\hline \multicolumn{7}{|c|}{ Constant Strabismus Amblyopia } \\
\hline $1 / 25$ & $\begin{array}{l}O S+2.00=-0.25 \times 130 \\
O D+2.25\end{array}$ & $\begin{array}{l}20 / 25 \\
20 / 15\end{array}$ & $1-2 \Delta \mathrm{ET}$ OS & $1 / 2 \Delta$ Nasal OS & ARC & Surgery, age 16 \\
\hline $2 / 23$ & $\begin{array}{l}O S+3.75=-0.50 \times 165 \\
O D+0.50\end{array}$ & $\begin{array}{l}20 / 30 \\
20 / 15 \\
\end{array}$ & $18 \triangle \mathrm{ET} O \mathrm{OS}$ & $1 \Delta \mathrm{Nasal}$ OS & $\ldots$ & Surgery, age 6 \\
\hline $3 / 15$ & $\begin{array}{l}\text { OS }-1.50 \\
\text { OD }-1.75\end{array}$ & $\begin{array}{l}20 / 122 \\
20 / 20\end{array}$ & $\begin{array}{l}10 \Delta E T \text { and } \\
1 \Delta H T \text { OS }\end{array}$ & $\begin{array}{l}2.5 \Delta \text { Nasal and } \\
2 \Delta \text { superior OS }\end{array}$ & ARC & No \\
\hline $4 / 32$ & $\begin{array}{l}\text { OS }+4.00 \\
\text { OD plano }\end{array}$ & $\begin{array}{c}20 / 277 \\
20 / 20\end{array}$ & $4 \triangle E T O S$ & $\begin{array}{l}16 \Delta \text { Nasal and } \\
4 \Delta \text { superior os }\end{array}$ & $\ldots$ & No \\
\hline $5 / 33$ & $\begin{array}{l}O S+0.75=-0.50 \times 40 \\
O D+0.25=-0.50 \times 180\end{array}$ & $\begin{array}{l}20 / 630 \\
20 / 10\end{array}$ & $\begin{array}{c}5-6 \Delta E T \text { and } \\
2 \Delta H T \text { OS }\end{array}$ & $\begin{array}{l}2.5-3.5 \Delta \mathrm{Nasal} \\
\text { and } 3-4 \Delta \mathrm{su}- \\
\text { perior OS }\end{array}$ & $\cdots$ & Surgery, age 8 \\
\hline \multicolumn{7}{|c|}{ Amblyopia Without Strabismus } \\
\hline $6 / 24$ & $\begin{array}{l}\text { OS }+-.75=-2.00 \times 90 \\
\text { OD p1 }=-0.50 \times 19\end{array}$ & $\begin{array}{l}20 / 38 \\
20 / 20\end{array}$ & None & $\begin{array}{l}2 \triangle \mathrm{Nasal} \text { and } \\
2 \text { inferior OS }\end{array}$ & NRC & No \\
\hline $7 / 25$ & $\begin{array}{l}\text { OS }-2.50=-1.25 \times 172 \\
\text { OD }-5.00=-0.75 \times 5\end{array}$ & $\begin{array}{l}20 / 25 \\
20 / 40\end{array}$ & $\begin{array}{l}\text { None } \\
\text { None }\end{array}$ & $\begin{array}{l}2 \Delta \text { Nasal and } \\
2 \Delta \text { inferior OD }\end{array}$ & NRC & No \\
\hline $8 / 19$ & $\begin{array}{l}\text { OS }+5.00 \\
O D+3.00\end{array}$ & $\begin{array}{l}20 / 110 \\
20 / 15\end{array}$ & None & $2 \Delta$ Temporal OS & NRC & $\begin{array}{l}\text { Orthoptics therapy, } \\
\text { age } 17\end{array}$ \\
\hline \multicolumn{7}{|c|}{ Intermittent Strabismus With and Without Mild Amblyopia } \\
\hline $9 / 22$ & $\begin{array}{l}\text { OS }-0.75=-0.25 \times 148 \\
\text { OD }-3.00=-0.25 \times 110\end{array}$ & $\begin{array}{l}20 / 20 \\
20 / 20\end{array}$ & $\begin{array}{l}\text { 18د ALT XT } \\
\text { and } 12\lrcorner \mathrm{HT}\end{array}$ & $\begin{array}{l}\text { Slight unsteady } \\
\text { central OU }\end{array}$ & NRC & No \\
\hline $10 / 31$ & $\begin{array}{l}O S-5.00 \\
O D-4.50=-0.75 \times 20\end{array}$ & $\begin{array}{l}20 / 20 \\
20 / 20 \\
\end{array}$ & $15 \Delta \times T$ OS & $\begin{array}{l}\text { Central. steady } \\
\text { OU }\end{array}$ & ARC & Surgery, age 16 \\
\hline $11 / 32$ & $\begin{array}{l}O S+0.75=-1.75 \times 180 \\
O D+1.25=-3.50 \times 5\end{array}$ & $\begin{array}{l}20 / 20 \\
20 / 23 \\
\end{array}$ & $40-50 \Delta X T O D$ & $\begin{array}{l}1 \Delta \text { Nasal and } \\
\text { superior, OD }\end{array}$ & ARC & $\begin{array}{l}\text { Orthoptics therapy, } \\
\text { age } 32\end{array}$ \\
\hline $12 / 25$ & $\begin{array}{l}\text { OS plano } \\
\text { OD }-1.00\end{array}$ & $\begin{array}{l}20 / 32 \\
20 / 16\end{array}$ & $\begin{array}{l}10 \Delta X T \text { and } \\
20 \Delta H T \text { OS }\end{array}$ & $1 / 2 \Delta$ Nasal, OS & ARC & No \\
\hline
\end{tabular}

${ }^{*}$ Abbreviations are as follows: ET, esotropia; HT, hypertropia; XT, exotropia; ALT, alternating; ARC, anomalous retinal correspondence; NRC, normal retinal correspondence; $\Delta$, prism diopter.

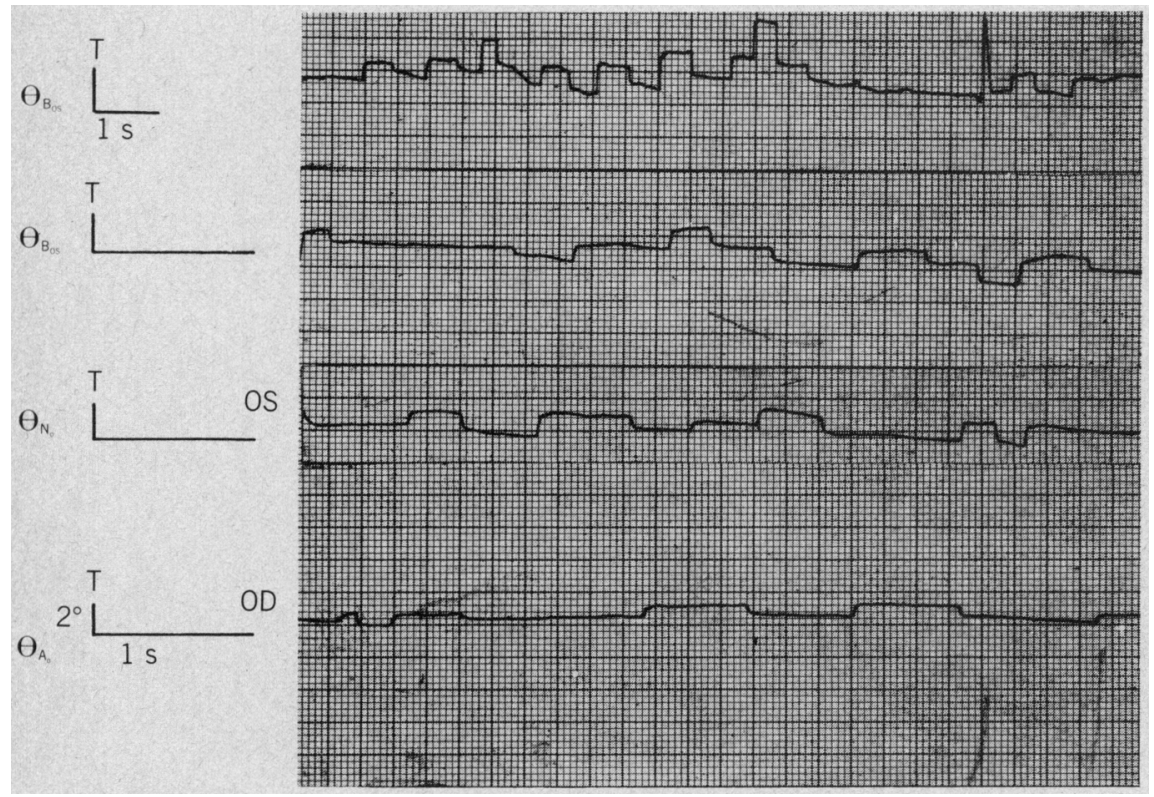

intrusions were rarely found in our three subjects with amblyopia with strabismus. The initiation of saccadic intrusions did not depend on the presence of considerable preceding drift, ie, drift amplitudes comparable in magnitude to saccadic amplitudes.
In the vast majority of cases, the initial saccade of the intrusion was not corrective in nature:

\section{Intermittent Strabismus}

Three subjects with intermittent strabismus exhibited saccadic intru-
Fig 1.-Eye position as function of time for subject 9 , who had intermittent strabismus and equal vision $(20 / 20)$ in each eye. From top to bottom, tracings are dominant left eye during binocular fixation (slow chart speed), dominant left eye during binocular fixation (fast chart speed), dominant left eye during monocular fixation, and nondominant right eye during monocular fixation. Saccadic intrusions are present under all viewing conditions and occur in the absence of marked preceding drift of eye. Symbols for this and subsequent figures are $\mathrm{T}$, templeward movement; $\mathrm{N}$, nasalward movement; $\Theta$, eye position. Subscripts are $o$, fellow eye occluded; $p$, fellow eye patched; T, target; B, binocular fixation; $N$, monocular fixation with normal (dominant) eye; A, monocular fixation with amblyopic eye; ND, monocular fixation with nondominant $(20 / 20)$ eye; OD, right eye; and $O S$, left eye.

sions under all test conditions. For example, subject 9, who had $20 / 20$ visual acuity in each eye, exhibited saccadic intrusions during monocular fixation with either eye as well as during binocular fixation. This is clearly shown in Fig 1 . In most 


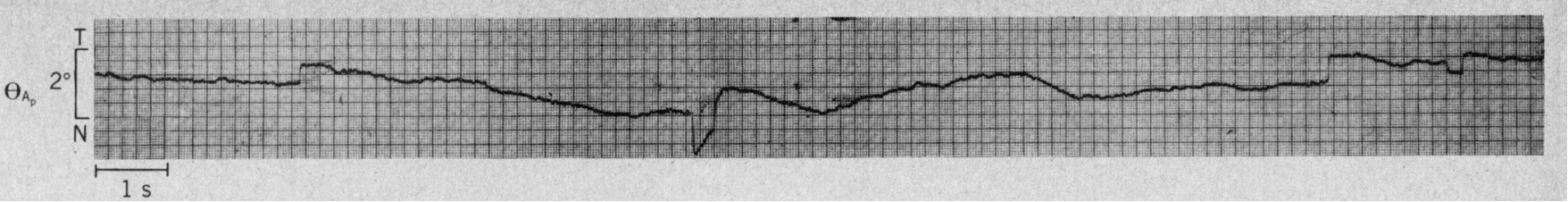

Fig 2.-Monocular fixation amblyopic eye in subject 8 , who had amblyopia without strabismus (20/110). Contrary to subjects with strabismus, few saccadic intrusions are evident in subjects with amblyopia only, probably in no greater incidence than found in some normal subjects. Prominent features of record are increased drift amplitudes and velocities.

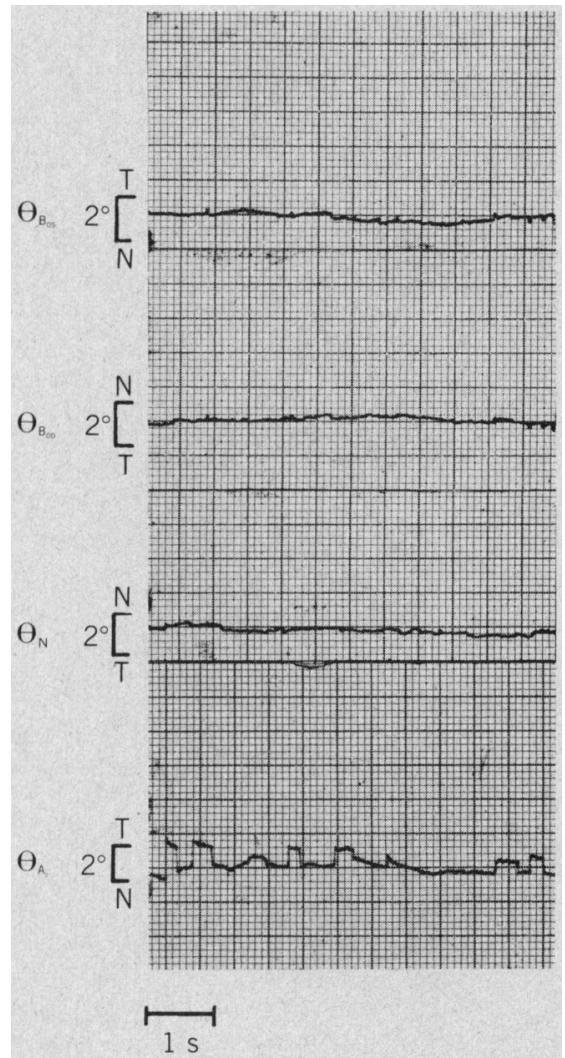

Fig 3.- Eye position as function of time for subject 4, who had constant strabismus amblyopia (20/277). From top to bottom, tracings are left and right eye during binocular fixation, monocular fixation normal eye, and monocular fixation amblyopic eye. Note presence of saccadic intrusions only during monocular fixation with amblyopic eye.

instances, the intrusions occurred without the presence of marked preceding drift. Although mean intrusion amplitude was greatest under binocular fixation conditions, intrusion frequencies were similar (about one per second) for all test conditions. The fourth subject (No. 11), with mild amblyopia (20/32), had normal fixation under all test conditions.

\section{Amblyopia Without Strabismus}

Saccadic intrusions were rarely found in subjects having amblyopia without strabismus, probably in no greater incidence than they might be found in normal subjects. A represen-

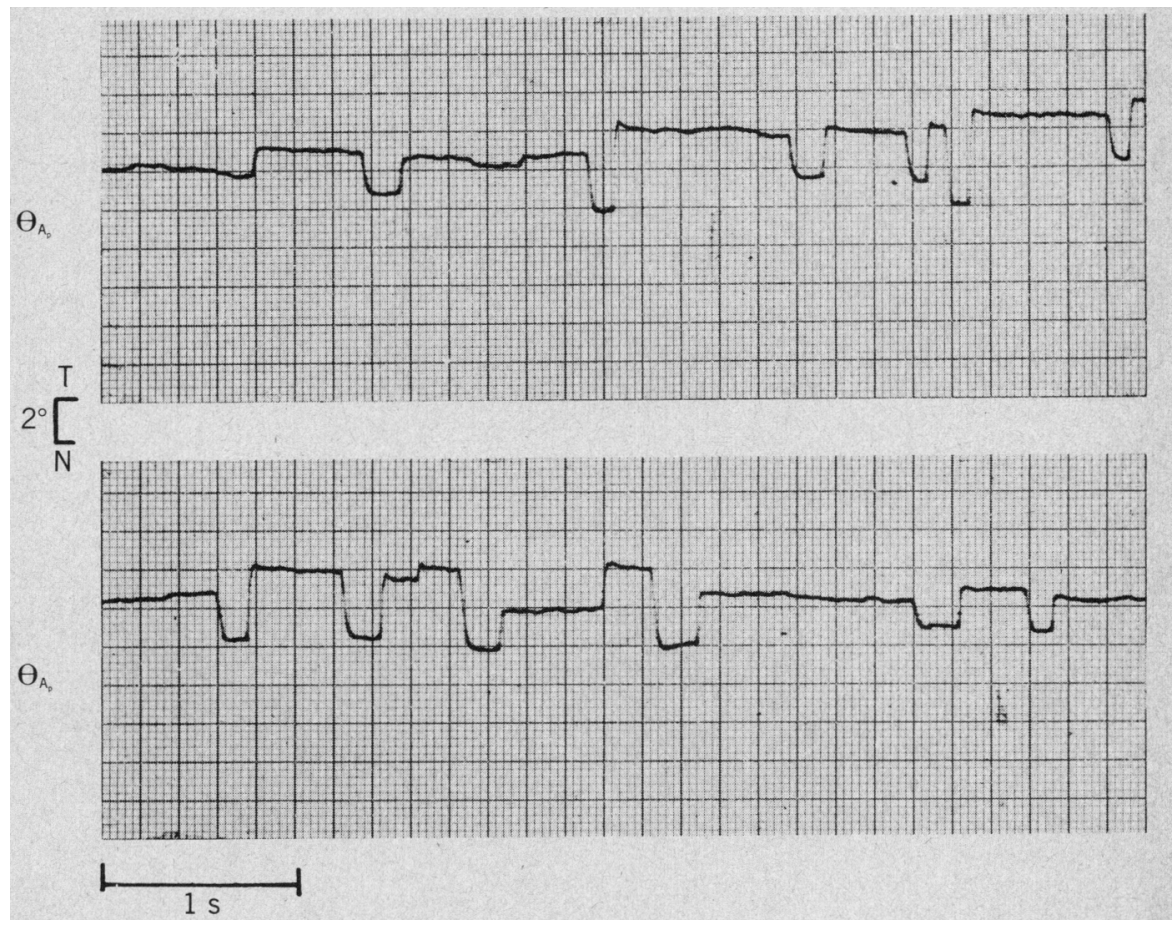

Fig 4.-Monocular fixation amblyopic eye in subject 3 , who had constant strabismus amblyopia (20/122). Trajectories and baselines of saccadic intrusions are clearly seen here with faster chart speed.

tative record is shown in Fig 2 for subject 8 . The prominent feature of the record is increased drift, with a paucity of large fixational saccades present.

\section{Constant Strabismus Amblyopia}

Saccadic intrusions were found during monocular fixation with the amblyopic eye in four of five subjects (No. 2 through No. 5) with constant strabismus amblyopia. Only in subject 2 were intrusions present during binocular fixation as well as during monocular fixation with the normal (dominant) eye. Eye movement records for subject $4(20 / 277)$ are presented in Fig 3. The similarity of the left and right eye traces during binocular fixation to the trace for monocular fixation with the normal eye is evident. These three traces are in marked contrast to the fixation record for the amblyopic eye, where templeward-initiated saccadic intrusions with amplitudes of $1^{\circ}$ to $2^{\circ}$ are present. Figure 4 shows the fixation record for subject $3(20 / 122)$; more typical nasalward-initiated saccadic intrusions with amplitudes of up to $4^{\circ}$ occur at a rate of approximately one per second. The $1^{\circ}$ templeward shift in baseline position that occurs midway in the top trace suggests a small change in mean eccentric fixation locus. A similar templeward fixation shift is also present in the lower trace (during seconds 2 and 3 ). There generally were steady intervals as long as 1 $\mathrm{s}$ in duration between saccadic intrusions. Fixation was within normal limits under all test conditions in subject 1 .

\section{Group Data}

The group data are presented in Fig 5 and Table 2. In Fig 5, saccadic amplitude during fixation is plotted 


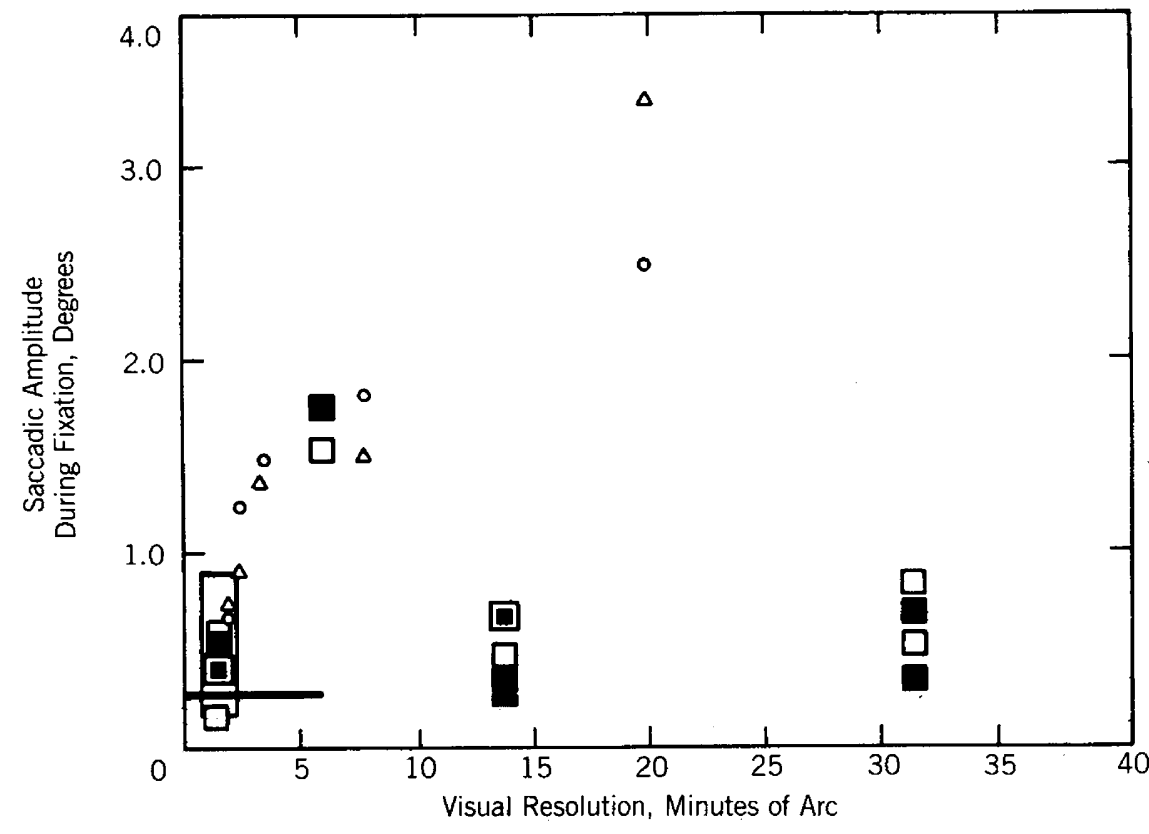

Table 2.-Saccadic Amplitude During Fixation in Patients With Strabismus*

\begin{tabular}{|c|c|c|c|c|}
\hline Subject & Mean $\pm 1 \mathrm{SD},{ }^{\circ}$ & Median, ${ }^{\circ}$ & $\begin{array}{c}\text { Sample } \\
\text { Size }\end{array}$ & Fixation \\
\hline \multicolumn{5}{|c|}{ Constant Strabismus Amblyopia } \\
\hline 1 & $<0.15$ WNL, A & $\ldots$ & $\ldots$ & Midline \\
\hline \multirow[t]{6}{*}{2} & $0.6 \pm 0.3 R, A$ & 0.55 & 86 & Midline \\
\hline & $0.6 \pm 0.2 \mathrm{~L}, \mathrm{~A}$ & 0.55 & 78 & Midline \\
\hline & $\overline{0.4 \pm 0.3 \mathrm{~A}}$ & 0.40 & 42 & Midline \\
\hline & $0.4 \pm 0.2 \mathrm{~A}$ & 0.40 & 30 & $5^{\circ}$ Left \\
\hline & $0.4 \pm 0.2 \mathrm{~N}$ & 0.40 & 20 & $2.5^{\circ}$ Left \\
\hline & $0.3 \pm 0.2 \mathrm{~B}$ & 0.25 & 12 & Midline \\
\hline 3 & $1.5 \pm 0.7 \mathrm{~A}$ & 1.75 & 84 & Midline \\
\hline \multirow[t]{3}{*}{4} & $0.7 \pm 0.4 \mathrm{~L}, \mathrm{~A}$ & 0.65 & 42 & Midline \\
\hline & $0.5 \pm 0.3 R, A$ & 0.35 & 22 & Midline \\
\hline & $0.5 \pm 0.3 \mathrm{~A}$ & 0.30 & 73 & Midline \\
\hline \multirow[t]{3}{*}{5} & $0.8 \pm 0.8 \mathrm{~A}$ & 0.70 & 32 & Midline \\
\hline & $0.8 \pm 0.7 \mathrm{~A}$ & 0.70 & 52 & Midline \\
\hline & $0.5 \pm 0.3 \mathrm{~A}$ & 0.35 & 42 & Midline \\
\hline \multicolumn{5}{|c|}{ Amblyopia Without Strabismus } \\
\hline $6-8$ & $<0.15$ WNL, A & & & Midline \\
\hline \multicolumn{5}{|c|}{ Intermittent Strabismus With and Without Mild Amblyopia } \\
\hline \multirow[t]{3}{*}{9} & $0.6 \pm 0.2$ "A" & 0.60 & 15 & Midline \\
\hline & $0.5 \pm 0.2 \mathrm{~N}$ & 0.45 & 17 & Midline \\
\hline & $0.9 \pm 0.6 \mathrm{~B}$ & 0.85 & 18 & Midline \\
\hline \multirow[t]{3}{*}{10} & $0.6 \pm 0.3$ "A" & 0.50 & 54 & Midline \\
\hline & $0.4 \pm 0.2 \mathrm{~N}$ & 0.35 & 27 & Midline \\
\hline & $0.4 \pm 0.2 \mathrm{~B}$ & 0.40 & 39 & Midline \\
\hline \multirow[t]{2}{*}{11} & $<0.15 \mathrm{WNL}, \mathrm{A}$ & $\ldots$ & $\therefore$ & Midline \\
\hline & $<0.15$ WNL, N & 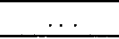 & $\ldots$ & Midline \\
\hline \multirow[t]{2}{*}{12} & $0.3 \pm 0.1 \mathrm{~A}$ & $0: 30$ & 36 & Midline \\
\hline & $0.4 \pm 0.1 \mathrm{~N}$ & 0.35 & 6 & Midline \\
\hline
\end{tabular}

*A indicates amblyopic eye; $N$, normal or dominant eye; B, binocular viewing; WNL, within normal limits; "A," nondominant eye of intermittent strabismic; $R$, saccades directed to the right; and $L$, saccades directed to the left.

as a function of visual resolution. For subjects with both intermittent and constant strabismus, the central tendencies were typically $1^{\circ}$ or less in amplitude. Thus, there was no direct relationship between saccadic ampli- tude during fixation and visual resolution. Subjects having amblyopia without strabismus exhibited fixational saccades that were within normal amplitude limits (generally less than 20 minutes).
Fig 5.-Saccadic amplitude during fixation as function of visual resolution. Data are from Table 2. Open squares represent mean saccadic amplitudes; filted squares represent median saccadic amplitudes in amblyopic eyes for our subjects with constant strabismus amblyopia. Triangles represent mean amplitudes for templeward-directed saccades, and open circles represent mean amplitudes for nasalwarddirected saccades of Schor's ${ }^{19}$ subjects with constant strabismus amblyopia. Range of mean and median saccadic amplitudes for our intermittent strabismic subjects for all test conditions is represented by vertical rectangle (in lower left corner). Saccadic amplitudes for our subjects having amblyopia without strabismus are represented by horizontal line (lower left corner); these are within normal limits. Note lack of direct relationship between mean or median saccadic amplitude and visual resolution in amblyopic (or nondominant) eye for our subjects. Central tendencies are generally less than $1^{\circ}$.

\section{Extensive Observations of Fixation in a High Amblyope}

Fixational eye movements in subject 5 , who had constant strabismus amblyopia (20/630), were studied under a variety of test conditions. Figure 6 (upper trace) shows monocular fixation with the amblyopic eye in which saccadic intrusions, single saccades, and drifts are present. Portions of this trace provide a good example of the steady fixation that was at times found in this high amblyope. At other times, saccadic intrusions were frequently observed. Saccadic intrusions could be elicited by redirecting the subject's attention to the fixation task, as shown in Fig 6 (lower trace). At the arrow, the experimenter verbally reminded the subject to continue looking closely at the target; a brief period of intrusions ensued. Interestingly, changes in instruction to strabismic or amblyopic subjects from "fixate carefully on the target" to "hold the eye steady" (in the presence of the target) could decrease fixational saccadic frequency by $50 \%$ to $90 \%$, similar to that found for normal persons $^{15}$; this has been reported elsewhere. ${ }^{116}$ Large refixation saccades were also present following step changes in target position (Fig 7). After steady fixation for several seconds, a $5^{\circ}$ step change in target position was introduced. This resulted in a series of saccades rather than a single saccade to refixate the target. Fixation ability was tested in still another way. The display screen and surrounding laboratory equipment could be seen by the subject in the 


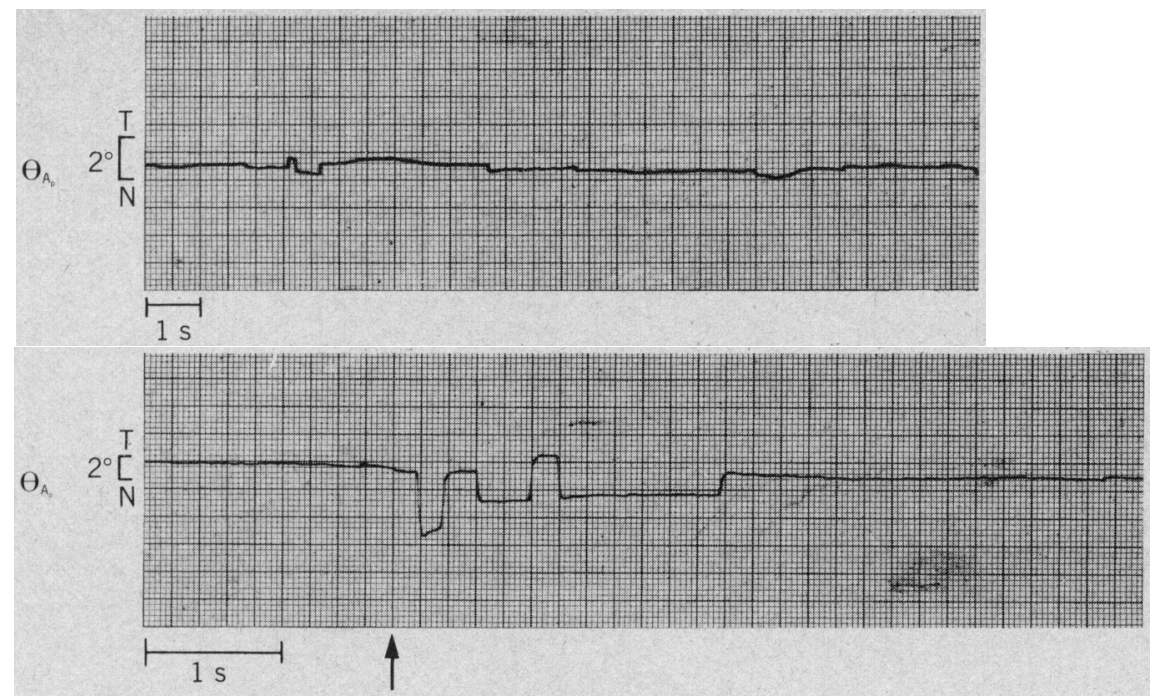

Fig 6.-Monocular fixation amblyopic eye in subject 5 , with constant strabismus amblyopia $(20 / 630)$. Upper trace shows remarkable steadiness (seen at times) of eye considering visual acuity is so low. In lower trace (at arrow), steadiness of fixation was disrupted when experimenter spoke to subject and redirected subject's attention to task. Baseline fixation area following these intrusions was approximately $1.5^{\circ}$ more nasal.

Fig 7.-Monocular fixation amblyopic eye in subject 5 , with constant strabismus amblyopia $(20 / 630)$. Note relative steadiness of eye before and shortly after $5^{\circ}$ change in stimulus position was introduced; in contrast, several refixation saccades occurred for a few seconds after target jump. Large deflections that moved pen off chart were due to blinks. L, left.
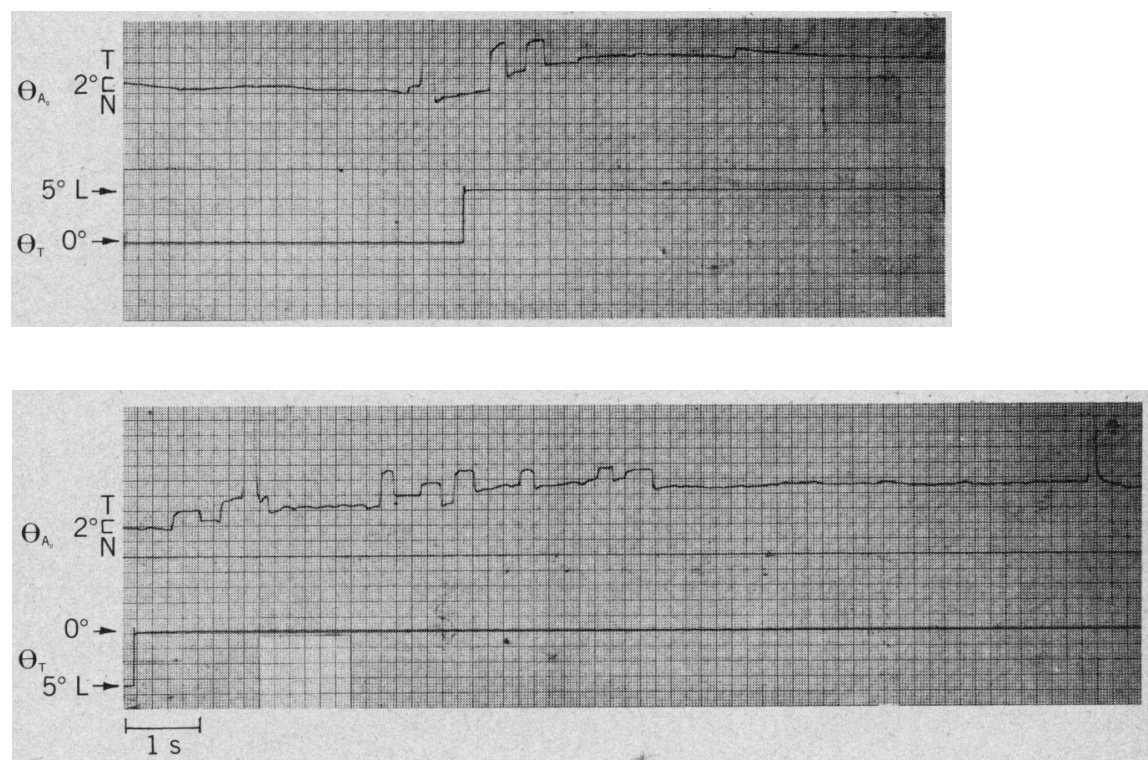

darkened room. The subject was asked to fixate the midline target. After several seconds the target was extinguished, and the subject was instructed to fixate where the target has previously appeared. The resulting amblyopic eye fixation pattern is shown in Fig 8. It is clear that the subject could not in this situation maintain as stable an eye position as when the fixation target was present; the presence of a target (visual feedback) appeared to aid in maintenance of steady fixation. Finally, the subject sometimes noted that the target appeared to "fade out" and disappear for short periods. To determine whether eye movements were related to target disappearance, we instructed the subject to look intently at the target and depress a switch held in the right hand whenever the target was no longer visible (the "Lawwill experiment" ${ }^{17}$ ). The results are presented in Fig 9. We initiated measurement by allowing for an assumed eyehand two-choice reaction time of 350 $\mathrm{ms.}^{18}$ On the average, approximately $100 \mathrm{~ms}$ following target disappearance the amblyopic eye began to drift nasally with an average velocity of $1.0^{\circ}$ per second; it continued to do so with an average amplitude of $2.5^{\circ}$ until the target was once again visible. The accumulated eye position error was corrected by either a single large saccade or, more typically, by multiple refixation saccades similar to those seen in Fig 6 and 7 where the subject's attention was redirected.

\section{COMMENT}

The preceding data illustrate rather clearly that the presence of saccadic intrusions was related to strabismus and not amblyopia. These findings confirm those of others regarding the presence of saccadic intrusions in constant strabismic amblyopia; but more importantly, they extend it to include subjects with intermittent strabismus and exclude those with amblyopia alone. Thus, for presumably the first time, a relationship between saccadic intrusions and strabismus is clearly demonstrated.

\section{Visual Acuity Unaffected by Saccadic Intrusions}

That intrusions do not adversely affect visual acuity was supported by the finding that they occurred in subjects with intermittent strabismus having normal visual acuity in each eye $(20 / 20)$. Furthermore, we have recorded saccadic intrusions during fixation in subjects with normal visual acuity free from strabismus, amblyopia, or neurologic disease (unpublished 


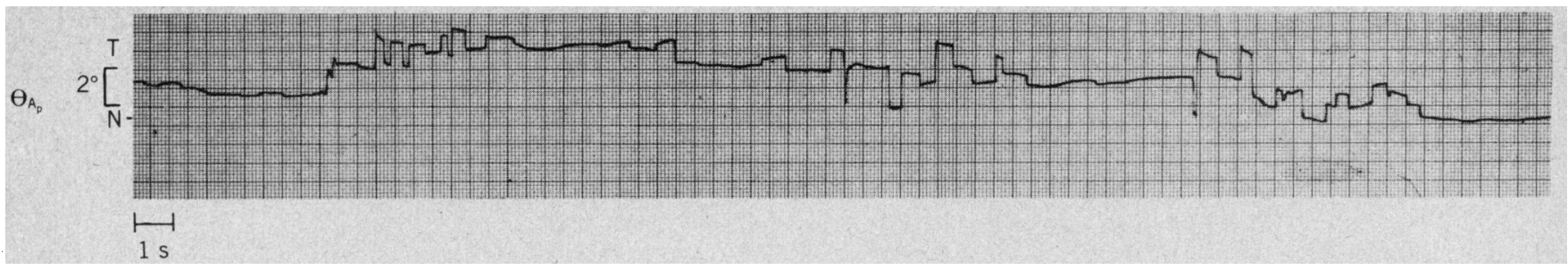

Fig 8.-Monocular fixation amblyopic eye in subject 5, with constant strabismus amblyopia (20/630). Subject was instructed to fixate where small target appeared before it was extinguished. Large saccadic intrusions, drift, and baseline changes indicate subject could not perform task well.

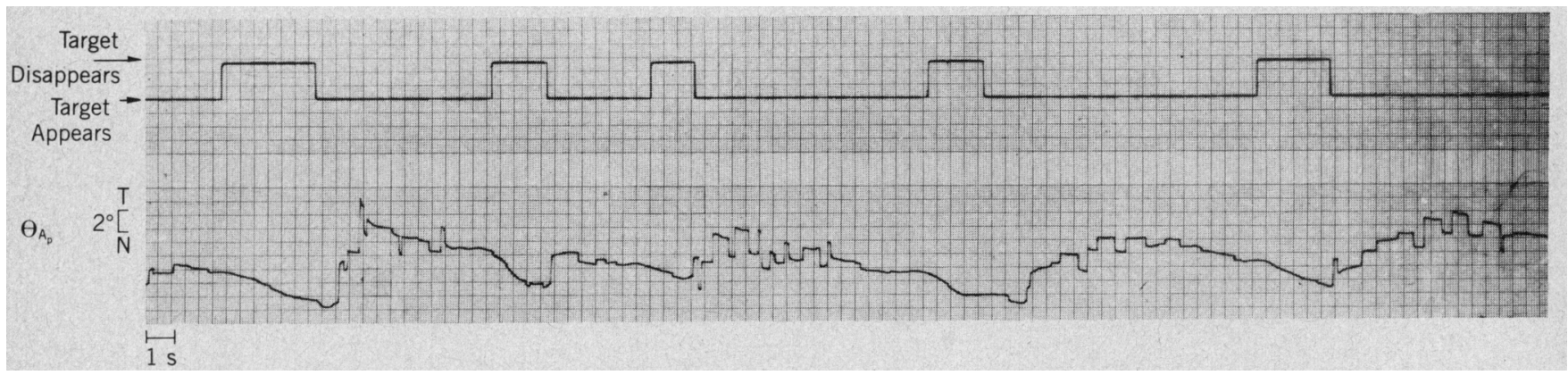

Fig 9.-Monocular fixation amblyopic eye in subject 5, with constant strabismus amblyopia (20/630) during objective demonstration of the Lawwill experiment. Lower trace is eye position, and upper trace is event marker indicating when target is not visible to subject. Note drift of eye after target disappears and saccadic return of eye toward center of screen when target is again visible.

data). This lack of interference by saccadic intrusions on visual acuity appears reasonable, since the intersaccadic interval for an intrusion was rarely shorter than $100 \mathrm{~ms}$ or longer than $400 \mathrm{~ms}$, thereby allowing adequate visual processing time during these periods. Furthermore, since intrusions generally averaged less than $1^{\circ}$ in amplitude, the change in visual resolution for those retinal areas used during the intrusion relative to the preferred fixation locus would not seriously impair resolving ability. In fact, it appeared to go unnoticed in our strabismic subjects during everyday binocular viewing conditions. Moreover, since saccadic intrusion frequency ranged from 0.3 to 2.0 per second, the interval during which a target and preferred fixation locus would be coincident also provided an adequate processing period. This lack of affect of saccadic intrusions on visual acuity in strabismics agrees with recent findings by Hess, ${ }^{12}$ who, in a tangentially related study, found similar contrast thresholds in amblyopic eyes during both stabilized and normal viewing conditions. The fact that intrusion direction in the amblyopic eye frequently (more than $70 \%$ of the time) occurred in the same direction as the squint suggests a fixation bias induced by the strabismus. Subjects with constant exotropia must be carefully studied and consist- ent results obtained before this hypothesis can gain support.

\section{No Relationship Between Saccadic Intrusion Amplitude and Visual Acuity and No Support for the Asymmetric 'Dead Zone' Theory}

Can the amplitude of saccadic movements during fixation in an amblyopic eye be predicted based only on its visual resolution? We found no relationship between mean or median saccadic amplitude and visual resolution in the amblyopic eye for either group of subjects with strabismus (Fig 5). This result is in striking contrast to the findings of Schor and Flom, ${ }^{13}$ who found a high correlation between these two variables in five constant strabismic amblyopes in whom median saccadic amplitude increased as visual acuity in the amblyopic eye decreased. They also developed a mathematic expression to predict median saccadic amplitude during fixation in the amblyopic eye based simply on visual resolution. The lack of agreement between the data of our subjects with constant strabismus and high amblyopia and theirs demonstrates the necessity of testing a large group of subjects before attempting to develop a general mathematic expression with high predictive power to relate eye movements to visual acuity in amblyopes.

Saccadic intrusions appear to be unrelated to abnormal eye position error detection in the amblyopic eye resulting from an asymmetric dead zone (believed to be due to hemiretinal suppression in the deviated eye). ${ }^{13}$ Nor does it appear to be related to function to correct for drift-induced position errors. This lack of correlation is suggested by several lines of information: (1) Subjects were able to follow random target step displacements to the left or right as small as $0.4^{\circ}$ in amplitude. (2) In many instances, the baseline position before and immediately after completion of a saccadic intrusion was similar, even though saccadic intrusion amplitudes showed much variability. (If a true dead zone existed, mean intrusion amplitudes would exhibit little variability.) (3) In many instances, considerable drift did not precede initiation of the intrusion. (4) When drifts did occur, the accumulated position error was usually corrected by a single, large saccade. (These could be as small as 5 minutes in amplitude, as measured during high-gain recordings.) Schor and Flom $^{1: 3}$ hypothesized that error-producing saccades were initiated to place the retinal image of the target outside this asymmetric dead zone, thus allowing the amblyopic eye to detect and correct the position error. On our reexamination of the original data ${ }^{19}$ we detected the presence of frequent large saccadic intrusions in 
the nonamblyopic eye during monocular fixation in some of their subjects. This does not support the dead zone hypothesis for the generation of saccadic intrusions, but it agrees with our finding of saccadic intrusions during monocular and binocular fixation in subjects with strabismus, especially of the intermittent variety.

\section{The Lawwill 'Fading' Experiment}

Lawwill ${ }^{17}$ made some interesting observations on amblyopic subjects that may provide a clue regarding a possible function of saccadic intrusions. While his subjects viewed letters on a distance acuity chart through a half-silvered mirror with the amblyopic eye, he viewed the fundus (of the amblyopic eye) with an infrared ophthalmoscope. He noted periods of steadiness along with intervals when the eye was estimated to have drifted as much as $2^{\circ}$ before subsequent movements returned the eye to the target. At times, the subjects reported fading of the target. Lawwill noted that the report of fading occurred as ocular drift began. The target reappeared at the end of the drift. He hypothesized that fading of the image may be due to an accelerated regional visual adaptation in amblyopic eyes and conducted other experiments that supported this hypothesis. While performing a similar experiment on one of our subjects, we confirmed Lawwill's experimental eye movement observations and, more importantly, succeeded in quantifying this phenomenon. Fading of the fixation target appears to initiate the ocular drift. Reappearance of the target, once it extends beyond this region of rapid adaptation, initiates the saccadic return movements. Thus, Lawwill's hypothesis appears to be the most likely explanation for these results.

How does this information relate to generation of saccadic intrusions? One function served by fixational eye movements in normal persons (usually occurring within an area less than 10 minutes in angular extent ${ }^{20}$ ) is to prevent visual adaptation. Artificial retinal image stabilization results in rapid disappearance of a target. ${ }^{21}$ Execution of frequent saccadic intrusions may be one way to prevent fading of the retinal image due to abnormally rapid visual adaptation occurring over small regions of the eye. Therefore, as has been suggested elsewhere, ${ }^{1.12}$ this may be an adaptive phenomenon. These local regions probably coincide with retinal areas that undergo suppression under binocular conditions in the deviated eye. The occurrence of intrusions in some of these subjects during fixation with the dominant eye or during binocular viewing, even though infrequent, suggests that the presence of strabismus may adversely affect oculomotor control during fixation in each eye, and thus may enter as a second factor in the generation of saccadic intrusions.

\section{Saccadic Intrusions in Intermittent Strabismus}

As was hypothesized in constant strabismus amblyopia, saccadic intrusions could result from abnormally rapid regional visual adaptation. At those times when the visual axes are divergent, ie, in exotropia, regions of the deviating eye typically undergo suppression. ${ }^{22-2+}$ The suppression that occurs in these subjects, while producing little, if any, amblyopia in either eye because of the intermittent nature of the defect, may still produce subtle abnormalities as early as the retinal level with a possible consequence being abnormally rapid regional visual adaptation. Moving the eyes over small angular extents helps prevent the image from fading. And, as hypothesized for a minority of subjects with constant strabismus amblyopia, the presence of strabismus may simply degrade fixation ability in both eyes.

This investigation was supported in part by training grant Ey-00076 from the National Eye Institute.

\section{References}

1. Ciuffreda KJ: Eye Movements in Amblyopia and Strabismus, thesis. School of Optometry, University of California, Berkeley, 1977.

2. Daroff RB: Ocular oscillations. Ann Otol Rhinol Laryngol 86:102-107, 1977.

3. Atkin A, Bender MB: "Lightening eye movements" (ocular myocionus). J Neurol Sci 1:2-12, 1964

4. Baloh RW, Konrad HR, Honrubia V: Vestibulo-ocular function in patients with cerebellar atrophy. Neurology 25:160-168, 1975.

5. Alpert JN, Coats AC, Perusquia E: "Saccadic nystagmus" in cerebellar atrophy. Neurology 25:676-680, 1975.

6. Selhorst JB, Stark L, Ochs AL, et al: Disorders in cerebellar ocular motor control: II. Macrosaccadic oscillation an oculographic control system and clinico-anatomical analysis. Brain 99:509-522, 1976.

7. Jung R, Kornhuber HH: Results of electronystagmography in man: The value of optokinetic, vestibular, and spontaneous nystagmus for neurologic diagnosis and research, in Bender $M$ (ed): The Oculomotor System. New York, Harper \& Row Publishers, 1964.

8. Feldon SE, Langston JW: Square-wave jerks: A disorder of microsaccades? Neurology
27:278-281, 1977.

9. Mackensen G: Das fixationsverhalten amblyopischer Augen. Albrecht von Graefes Arch Ophthalmol 159:200-211, 1957.

10. von Noorden G, Mackensen G: Phenomenology of eccentric fixation. Am $J$ Ophthalmol 53:642-661, 1962.

11. Von Noorden G, Burian HM: An electrooculographic study of the behavior of the fixation of amblyopic eyes in light- and dark-adapted state: A preliminary report. Am $J$ Ophthalmol 46:68-77, 1958 .

12. Hess RF: Eye movements and grating acuity in strabismic amblyopia. Ophthaimic Res 9:225-237, 1977.

13. Schor C, Flom MC: Eye position control and visual acuity in strabismus amblyopia, in Lennerstrand G, Bach-y-rita P (eds): Basic Mechanisms of Ocular Motility and Their Clinical Implications. New York, Peragmon Press, 1975.

14. Stark L, Vossius G, Young LR: Predictive control of eye tracking movements. Inst Radio Eng Trans Hum Factors Electron 3:52-57, 1962.

15. Steinman RM, Cunitz RJ, Timberlake GT, et al: Voluntary control of microsaccades during maintained monocular fixation. Science 155:1577$1579,1967$.
16. Ciuffreda KJ, Kenyon RV, Stark L Suppression of saccadic intrusions in strabismic and anisometropic amblyopia. Ophthalmic Res 11:31-39, 1979

17. Lawwill $\mathrm{T}$ : Local adaptation in functional amblyopia. Am $J$ Ophthalmol 65:903-906, 1968.

18. McCormick EJ: Human Factors in Engineering and Design, ed 4. New York, McGrawHill Book Co, 1976, p 185.

19. Schor C: Oculomotor and Neurosensory Analysis of Amblyopia, thesis. School of Optometry, University of California, Berkeley, 1972.

20. Ratliff F, Riggs LA: Involuntary motion of the eye during monocular fixation. $J$ Exp Psychol 40:687-701, 1950.

21. Ditchburn RW: Eye Movements and Visual Perception. Oxford, England, Clarendon Press, 1973.

22. Jampolsky A: Characteristics of suppression in strabismus. Arch Ophthalmol 54:683-696, 1955.

23. Nawratzki I, Jampolsky A: Regional hemiretinal difference in amblyopia. Am J Ophthalmol 46:339-344, 1958.

24. Pratt-Johnson J, Wee HS: Suppression associated with exotropia. Can J Ophthalmol 4:136-144, 1969. 